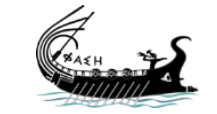

journal.phaselis.org
PHAS LLIS

Issue IV (2018)
Disiplinlerarası Akdeniz Araştırmaları Dergisi

Journal of Interdisciplinary Mediterranean Studies

\title{
Phaselis'teki Bazı Biyositlerin Tarihi Eserlerden İzole Edilen Siyah Mikrokoloniyal Mantarlara Etkileri
}

\author{
The Effects of some Biocides in Phaselis Against Black \\ Microcolonial Fungi Isolated from Historical Monuments
}

\author{
Hacer BAKIR SERT - Fatma AKDENIZ
}

open 2 access journals

The entire contents of this journal, Phaselis: Journal of Interdisciplinary Mediterranean Studies, is open to users and it is an 'open access' journal. Users are able to read the full texts, to download, to copy, print and distribute without obtaining the permission of the editor and author(s). However, all references to the articles published in the e-journal Phaselis are to indicate through reference the source of the citation from this journal.

Phaselis: Journal of Interdisciplinary Mediterranean Studies is a peer-reviewed journal and the articles which have had their peer reviewing process completed will be published on the web-site (journal.phaselis.org) in the year of the journal's issue (e.g. Issue III: JanuaryDecember 2017). At the end of December 2016 the year's issue is completed and Volume IV: January-December 2018 will begin.

Responsibility for the articles published in this journal remains with the authors.

Citation H. Sert, F. Akdeniz, "Phaselis'teki Bazı Biyositlerin Tarihi Eserlerden İzole Edilen Siyah Mikrokoloniyal Mantarlara Etkileri". Phaselis IV (2018) 47-56.

http://dx.doi.org/10.18367/Pha.18003

Received Date: 18.01.2018 | Acceptance Date: 09.02.2018

Online Publication Date: 13.02.2018

Editing Phaselis Research Project

www.phaselis.org 


\title{
Phaselis'teki Bazı Biyositlerin Tarihi Eserlerden İzole Edilen Siyah Mikrokoloniyal Mantarlara Etkileri
}

\author{
The Effect of some Biocides in Phaselis Against Black Microcolonial Fungi Isolated from \\ Historical Monuments
}

\author{
Hacer BAKIR SERT* Fatma AKDENIZ*
}

\begin{abstract}
Öz: Son yıllarda mantar ve likenlerin binalar ve özellikle tarihi-kültürel yapılarda meydana getirdikleri zararlar daha iyi anlaşılmaya başlanmış ve bu yapıların korunmasına yönelik araştırmalar oldukça önem kazanmıştır. Mermer, kireçtaşı, kumtaşı gibi taşlardan oluşan birçok yapı, bu biyolojik tehlike ile karşı karşıyadır. Bu organizmaların sadece organik maddeleri değil, aynı zamanda çeşitli mineraller, kayalar, maden cevherleri, camlar, metaller ve alaşımlarını da etkiledikleri kesin olarak ortaya çıkmıştır. Tarihi eserlerde estetiği önemli derece bozan renk değişimleri, tortulaşmalar, kopmalar-kırılmalar bu organizmaların başlıca etkilerindendir. Bu çalışma kapsamında tarihi eserleri korozyona uğratan siyah mikrokoloniyal mantarların üremesini durdurmaya yönelik kullanılan biyositlerden Preventol A8, Preventol R80, Alkil Benzil Dimetil Amonyum Klorid, Trisiklazol (melanin inhibitör), Bismut 2-3 dimerkaptopropanol, Polietilenimin (permeabilizatör), Antimoos'un etkileri araştııı mıştır. Çalışma alanı olarak ülkemizin en önemli tarihi merkezlerinden birisi olan Phaselis antik kenti seçilmiştir.
\end{abstract}

Anahtar sözcükler: Phaselis, Tarihi Eser, Mikromantar, Korozyon, Biyosit

Abstract: During recent years, damage caused by lichens and fungi on buildings, particularly on ancient buildings and monuments, have been better understood and have acquired a considerable significance. Many ancient structures built or carved from rock, such as marble and limestone, are subject to this threat. It is definitively shown that these microorganisms affected not only the organic materials but also various minerals, rocks, mine ores, glass, metals and alloys. The main effects of these microorganisms on the stones are: color change and flaking on the facades of buildings considerably impairing their visual appearance. In this study the effects of some biocides (Preventol A8, Preventol R80, Alcyl Benzyl Dimethyl Amonium Chlorid, Tricyclazol (melanin inhibitor), Bismut 2-3 dimerkaptopropanol, Polietylenimin (permeabilizatör), Antimoos) on serious biodeteriorationspotential of monument inhabiting black microcolonial fungi. Phaselis antique city was chosen, because of their historical significance in Turkey.

Keywords: Phaselis, Historical Monument, Microfungi, Corrosion, Biocide

Giriş

Tarihi eserlerin mikrobiyolojik yönden tehdidi ülkemizde henüz çok yeni araştırılmaya başlanan bir konudur. Günümüzde tarihi ve kültürel varlıkların korunması ile ilgili çalışmalarına verilen

* Prof. Dr., Akdeniz Üniversitesi, Manavgat Turizm Fakültesi, Antalya. hacersert@akdeniz.edu.tr

** MA, Akdeniz Üniversitesi, Fen Bilimleri Enstitüsü, Biyoloji Bölümü, Antalya, fakdeniz@mail.com

Bu projeyi destekleyen Akdeniz Üniversitesi Bilimsel Araştırma Projeleri Yönetim Birimi'ne ve uygulamalarda desteğini esirgemeyen Dr. Ulrike Tauer'e (University of Natural Resorces and Applied Life Sciences) teşekkürlerimi sunarım. 
önem artmıştır. Kültürel mirasın korunup, mimari, tarihi ve estetik özelliklerini kaybetmeden gelecek nesillere aktarılabilmesi için öncelikle onlara zarar veren etkenlerin tam olarak belirlenmesi, ardından korunma ve bakım için en doğru yöntemlerin seçilmesi çok önemlidir. Tarihi eserlerde bakım, onarım, restorasyon ve konservasyon işlemlerinde yapıya zarar veren, görüntüyü bozan organizmaların yok edilmesi ya da gelişimlerinin kontrol altına alınması için biyosidal ürünler kullanılır. Yapılar kimyasal maddeler kullanılmadan da alınabilecek önlemlerle bu etkilere karşı bir dereceye kadar dirençli hale gelebilmekte fakat risk faktörlerinin sürekli ve şiddetli olması durumunda kimyasal önlemlere gereksinim duyulmaktadır.

Bu çalışmada bakım, onarım, restorasyon ve konservasyon işlemlerinde siyah mikrokoloniyal mantarları yok etmek veya gelişimlerini kontrol altına almak için kullanılan biyositlerin organizma üzerinde farklı dozlarda gösterdiği etkiler araştııımıştır. Böylece hem bu mikroorganizmaların biyositlere olan direnci belirlenmiş hem de sentetik kimyasalların aşırı ve düzensiz kullanımının önüne geçilerek, tarihi eserleri mikromantarlardan korumak üzere kullanılan biyositlerin insan ve çevre sağlığı, hedef dışı faydalı canlılar, toprak mikroflorası, toprak verimliliği üzerindeki olumsuz etkilerinin en aza indirgenmesi hedeflenmiştir.

Binalar ve tarihi yapılar mikromantarların hem mekanik hem de fizyolojik etkilerine maruz kalırlar. Mikromantarlar salgıladıkları asitler, mekanik delme veya taşın içerisinde çoğalarak büyüme ile taşların yapılarını bozarlar, parçalanarak ufalanmalarını sağlarlar. Mantarların mekanik etkileri doğal kayaçların yanısıra binalardaki tuğla ve betonlar da da gözlenir ${ }^{1}$. Mantarlar taş ile temas ettiği zaman ilk olarak yüzeye sıkıca tutunurlar. Daha sonra çok ince hifleri yardımı ile taşın kristal yapısı içerisine nüfuz ederler. Hifler taşın içerisinde buldukları çatlak ve boşlukları takip ederek buralarda yeni koloniler oluştururlar. Bu koloniler içeride büyüdükçe oluşan yüksek iç basınç taşın çatlamasına veya parçanın kırılıp düşmesine neden olur. Bulaşma, yapışma ve parça kaybı tekrar eden bir süreçtir. Hifler sürekli taşın derinliklerinde ilerleyerek içeride yeni boşluklarda yeni koloniler oluşturur². Şu ana kadar oldukça yavaş işleyen bu süreci belirleyecek ve koIonilerin taşın üstünde büyümelerini doğrudan izleyebileceğimiz bir metot geliştirilememiştir.

Havanın çok nemli olmasından dolayı özellikle Akdeniz ülkelerindeki tarihi eserlerde mikromantarlara oldukça sık rastlanmaktadır. Diakumaku et al. 1995, Hawksworth 1969, Krumbein 1969, Ellis 1971-1976, Gorbushina et al. 1994, de Hoog \& Guarro 1995, Sterflinger et al. 1997, Wollenzien et al.1997, de Leo et al. 1999, Bogolomova \& Minter 2003, Selbmann et al. 2004, Bills et al. 2004, Ruibal et al. 2005, Sert et al. 2007a, b, gibi çalışmalarda elde edilen sonuçların zenginliği bunu kanıtlamaktadır. Akdeniz iklimine sahip ülkelerde yapılan çalışmalarda en sık rastlanan cinsler, siyah mikromantarlardan Coniosporium, Sarcinomyces, Capnobotryella, Phaeococcomyces ve Rhinocladiella'dır.

Son yıllarda mikromantarların binalar ve özellikle tarihi-kültürel yapılarda meydana getirdikleri zararlar daha iyi anlaşımaya başlanmış ve bu yapıların korunmasına yönelik araştırmalar oldukça önem kazanmıştır. Mermer, kireçtaşı, kumtaşı gibi taşlardan oluşan birçok yapı, bu biyolojik tehlike ile karşı karşıyadır. Bu organizmaların sadece organik maddeleri değil, çeşitli mineraller, kayalar, maden cevherleri, camlar, metaller ve alaşımlarını da etkiledikleri kesin olarak ortaya çıkmıştır. Taş yapılar üzerinde çok farklı büyüklüklerde koloniler meydana getiren büyüklüğü $2 \mu \mathrm{m}$ ile $2 \mathrm{~cm}$ arasında değişebilen krater şeklindeki çukurların oluşmasına neden olan siyah

Eckhard 1985; Gravesen et al. 1994.

Sterflinger \& Krumbein 1997, Sterflinger et al. 1999. 
mikro-mantarlardan oluşan grup üyelerinin (Dematiaceae, Hyphomycetes) meydana getirdiği estetik olmayan renk değişimleri, üst yüzeyin ufalanarak parçalanmasıyla parça kayıpları sonucunda lahitler ve diğer yapılar üzerindeki kabartma yazıların okunması, resimlerin tanınma güçlüğü gibi estetik görüntüde de bozulma meydana gelir.

Birçok medeniyetin beşiği olan ülkemizde tarihi eserlerin korunması için tehdit unsurlarının belirlenerek incelenmesi, daha sonra bu tehdit unsurlarının ortadan kaldırılması için gerekli çaıışmaların yapılması gerekmektedir. Tarihi eserlerin bakımı, korunması çalışmalarına önemli katkılarda bulunacak olan bu araştırmada siyah mikromantarların gelişimine bazı biyositlerin farklı dozlarının etkileri belirlenip sonuçlar karşılaştırıımıştır.

Tarihi eserlerin yüzeylerinde meydana gelen renk değişimleri, mantar-liken kolonileri ve tortulaşmanın giderilmesi, diğer bir deyişle temizlenmesi için çeşitli mekanik uygulamalar yapılmasının yanında kimyasal maddeler de kullanılmaktadır. Bu maddeler kullanılmadan da alınabilecek önlemlerle yapılar bu etkilere karşı bir dereceye kadar dirençli hale gelebilmekte, fakat risk faktörlerinin sürekli ve şiddetli olması durumunda kimyasal önlemlere mutlaka gereksinim duyulmaktadır. Kültürel yapıların bakım, onarım, restorasyon ve konservasyon işlemlerinde yapıya zarar veren, görüntüyü bozan organizmaların yok edilmesi ya da gelişimlerinin kontrol altına alınması için kullanılan kimyasal maddelerin uzun vadede doğal ekosisteme verebileceği zarar intimalini en aza indirgemek için kullanılan dozların hedef organizma üzerinde etkinliğinin test edilip düzenlenmesi gerekir.

Türkiye`nin tarihi eserler yönünden en zengin antik kentlerinden birisi olan Phaselis'te bulunan eserlerde mikrobiyal korozyonun çok ileri seviyede olması, antik kent için büyük bir tehdit olarak görülmesi böyle bir çalışmanın yapılması gerekliliğini ortaya çıkarmıştır. Dolayısıyla tarihi eserlerin bakımı, onarımı gibi işlemlerde kullanılan biyositlerden Preventol A8, Preventol R80, Alkil Benzil Dimetil Amonyum Klorid, Trisiklazol (melanin inhibitör), Bismut 2-3 dimerkaptopropanol, Polietilenimin (permeabilizatör) ve Antimoos'un farklı dozlarının bu organizmalar üzerindeki etkileri araştırılmıştır.

\section{Materyal ve Yöntem}

Phaselis antik kentinde gerçekleştirilen bu çalışmada, biyosit etki denemeleri için tarihi eserlerin bakımı-korunması çalışmalarında kullanılan biyositlerden olan Preventol A8, Preventol R80, Alkil Benzil Dimetil Amonyum Klorid, Trisiklazol (melanin inhibitör), Bismut 2-3 dimerkaptopropanol, Polietilenimin (permeabilizatör) ve Antimoos uygulanmıştır. Üzerinde uygulama yapılacak olan örnekler şu lokalitelerden alınmıştır:

Lokalite I: Antalya; Olimpos Milli Parkı; Phaselis Antik Kenti; Imparatora adanmış kutsal alan ve Tiyatro çevresi, K 36 31.22'- D 30³3.05', 15-25 m, 13.ix.2014

Lokalite II: Antalya; Olimpos Milli Parkı; Phaselis Antik Kenti; Kumluca-Antalya Otoyolu güneyi, otel yapımı planlanan alan, $\mathrm{K} 36^{\circ} 31.32^{\prime}-\mathrm{D} 30^{\circ} 31.45^{\prime}, 20$ - $30 \mathrm{~m}$, 13.ix.2014

Lokalite III: Antalya; Olimpos Milli Parkı; Kumluca-Antalya Otoyolu kuzeyi, Tahtalı dağı güney etekleri; Antik teraslar, K 36³2.19'- D 30³1.13', 280 m, 13.ix.2014

Lokalite IV: Antalya; Olimpos Milli Parkı; Kumluca-Antalya Otoyolu kuzeyi, Tahtalı dağı güney etekleri; Servi topluluğu, K 36³ 32.47'- D 30³0.08', 440 m, 13.ix.2014

Lokalite V: Antalya; Olimpos Milli Parkı; Kumluca-Antalya Otoyolu kuzeyi, Tahtalı dağı güney etekleri; Teleferik başlangıç noktası K 36³2.23'- D 30²9.07', 730 m, 13.ix.2014 


\section{Uygulama esnasında:}

I. Birbirinden farklı taş yapısına sahip olan tarihi eserlerden alınan örneklerin üzerine su ile hazırlanmış \% 0.01, 0.1, 1 ve 3'lük biyosit çözeltileri direkt olarak püskürtme yöntemiyle uygulanmış, biyositlerin cinsine bağlı olarak değişen etki süresi sonunda (24-48 saat) uygulama yapılan bölge yıkanmıştır. Uygulama sonrasında tarihi eserlerin mikromantarlar tarafından enfekte olmuş kısımlarından milimetrik boyutlardaki taş parçacıkları kazınıp alınarak TTC (Trifenil Tetrazolyum Klorid) testine tabi tutulmuştur. Kontrol uygulaması için aynı tarihi eserin belirli bir alanına biyosit uygulanmayıp direkt olarak örnek alınmış ve TTC testine tabi tutulmuştur.

TTC Testi: \% 0.2 TTC çözeltisi bulunduran ve dışı alüminyum folyo ile tamamen sarııı tüpler içerisinde $28^{\circ} \mathrm{C}$ de 24 saat inkübe edilmiştir. İnkübasyon süresi sonunda kırmızı renkle boyanan bölgeler o kısımda hala canlıığın olduğunu göstermektedir. Uygulamanın ardından hiflerin gelişimlerinin ayrıntılı olarak gözlenebilmesi için taş parçacıkları mikroskopta incelenmiştir.

II. Siyah mikrokolonial mantarlar tarihi eserlerden izole edilip besiyerinde oda sıcaklığında yetiştirilmiştir. Siyah mikro mantarların taşlardan izolasyonu için taş parçaları \% 70 'lik alkolle yıkandıktan sonra stereo mikroskop altında incelenmiş ve koloniler tek tek steril kanallı iğneyle alınarak malt extrakt agar (MeA) ve dichloran rose bengal(DRBC) besiyerlerine aktarılmıştır. Besiyerlerinde gelişimi sağlanan mantarlar petri kaplarından tekrar izole edilerek malt extrakt agar ve czapek agar(CzA) besiyerlerine ekilmiştir.

Besiyeri üzerinden steril bistüri yardımıyla kazınarak alınan koloniler ile \%1 lik Tween 80 çözeltisi ile oluşturulan süspansiyon steril tüplere aktarılmıştır. Süspansiyondaki sporlar Thoma lamında sayılarak 10 üzeri 6 spor/ml olacak şekilde solüsyon hazırlanmıştır. Daha sonra bu spor solüsyonundan 1'er ml alınarak önceden hazırlanan MeA içeren petri kaplarına aktarılmış ve steril drigalski spatülü ile sporların besiyeri yüzeyine tamamen yayılması sağlanmıştır. Biyositlerden steril su ile elde edilen farklı dozlardaki çözeltilerden (\% 0.01, \% 0.1, \% 1, \% 3) besiyeri üzerine açılan çukurlara $50^{\prime}$ şer $\mu$ l pipetlenmiştir. Pipetleme işlemleri bittikten sonra $28{ }^{\circ} \mathrm{C}$ de $24-48$ saat inkübasyona bırakılmıştır. Kontrol uygulaması için her örnekten birer adet biyosit uygulaması yapılmadan ayırılmıştır.

Biyositlerin etki denemeleri değerlendirilirken siyah mikromantarların cinsleri de göz önünde bulundurularak sonuçlar belirtilmiştir.

\section{Bulgular}

Tarihi yapılar uygarlıkların mirası olarak bırakılan kültür varlıklarıdır. Bu anıtların bakımı iyi yapılamadığından, günden güne yıpranarak mimari, tarihi ve estetik özelliklerini kaybetmektedirler. Phaselis antik kenti ülkemizin en önemli tarihi ve turistik değerlerini barındıran önemli bir merkezdir. Fakat araştırma esnasında antik kent merkezinde bulunan tarihi eserlerde oldukça fazla mikrobiyal tahribat olduğu gözlemlenmiştir. Bu tahribat yapıların üzerinde yaşayan bakterilerin, mantar ve likenlerin etkisiyle ortaya çıkmıştır. Özellikle siyah mikrokoloniyal mantarlar Phaselis'deki tarihi eserlerin yüzeyinde estetiği bozan renk değişimleri meydana getirmiştir. Bu renk değişimlerinde en fazla göze çarpan renk siyah olmakla birlikte kahverengi, kırmızı, turuncu ve benzeri renklerde kolonilere de rastlamak mümkündür. Siyah mikrokoloniyal mantarlar yüzeyde küçük ve çok sayıda koloniler oluşturup bir süre sonra ardında bu kolonilerin meydana getirmiş olduğu çukurları bırakmıştır. Ayrıca bu mikromantarların salgıladıkları asitler; hiflerinin taş içerisinde ilerlemesi ve bundan dolayı oluşan iç basınç nedeniyle taşların parçalanarak ufalandığı gözlemlenmiştir. 
Phaselis Antik Kenti'nde belirlenen 5 ayrı lokalitede, tarihi eserlerin bakımı-korunması çalışmalarında kullanılan biyositlerden olan Preventol A8, Preventol R80, Alkil Benzil Dimetil Amonyum Klorid (ABDAK), Trisiklazol (melanin inhibitör), Bismut 2-3 dimerkaptopropanol(Bi2-3DMP), Polietilenimin (permeabilizatör) ve Antimoos'un \% 0.01, \% 0.1, \% 1, \% 3'lük konsantrasyonları uygulanmış ve koIoni sayılarının ortalamaları aşağıdaki tabloda verilmiş̧ir (Tablo 1).

Tablo 1. Çalışmada kullanılan biyositlerin farkı konsantrasyonlarının etkilerini gösteren uygulama sonuçları (Ortalama koloni sayıları).

\begin{tabular}{|l|c|c|c|c|c|}
\hline $\begin{array}{c}\text { Biyosit / Örnek alınan lokalite } \\
\text { (Uygulama alanı) }\end{array}$ & I & II & III & IV & V \\
\hline Preventol A8 \% 0.01 & 6700 & 6300 & 5900 & 4000 & 7000 \\
\hline Preventol A8 \% 0.1 & 6100 & 6000 & 3600 & 3500 & 6400 \\
\hline Preventol A8 \% 1 & 1300 & 1500 & 3000 & 2000 & 1500 \\
\hline Preventol A8 \% 3 & 300 & 250 & 500 & 200 & 450 \\
\hline Preventol R80 \% 0.01 & 5500 & 5000 & 4900 & 3000 & 6000 \\
\hline Preventol R80 \% 0.1 & 4800 & 3600 & 3500 & 2600 & 5000 \\
\hline Preventol R80 \% \% 1 & 250 & 250 & 200 & 230 & 400 \\
\hline Preventol R80 \% 3 & 120 & 130 & 110 & 100 & 300 \\
\hline ABDAK \% 0.01 & 8600 & 8000 & 7600 & 7000 & 9700 \\
\hline ABDAK \% 0.1 & 3000 & 2800 & 2700 & 2400 & 4000 \\
\hline ABDAK \% 1 & 2800 & 2500 & 2100 & 1980 & 3900 \\
\hline ABDAK \% 3 & 350 & 280 & 280 & 230 & 450 \\
\hline Trisiklazol \% 0.01 & 9000 & 8000 & 7600 & 7000 & 10040 \\
\hline Trisiklazol \% 0.1 & 7600 & 7500 & 6900 & 6000 & 9000 \\
\hline Trisiklazol \% 1 & 2200 & 2200 & 2000 & 1900 & 4500 \\
\hline Trisiklazol \% 3 & 250 & 340 & 300 & 230 & 500 \\
\hline Bi2-3DMP \% 0.01 & 5500 & 5000 & 4900 & 4000 & 7000 \\
\hline Bi2-3DMP \% 0.1 & 4000 & 3800 & 3800 & 2500 & 5000 \\
\hline Bi2-3DMP \% 1 & 560 & 500 & 450 & 450 & 790 \\
\hline Bi2-3DMP \% 3 & 230 & 340 & 320 & 260 & 560 \\
\hline Polietilenimin \% 0.01 & 8900 & 6900 & 6000 & 4500 & 11000 \\
\hline Polietilenimin \% 0.1 & 5600 & 4400 & 4000 & 3000 & 6000 \\
\hline Polietilenimin \% 1 & 340 & 250 & 250 & 240 & 1200 \\
\hline Polietilenimin \% 3 & 160 & 130 & 120 & 100 & 700 \\
\hline Antimoos \% 0.01 & 9000 & 7800 & 6700 & 6500 & 9000 \\
\hline Antimoos \% 0.1 & 570 & 590 & 460 & 480 & 900 \\
\hline Antimoos \% 1 & 200 & 190 & 190 & 200 & 500 \\
\hline Antimoos \% 3 & 4300 & 4000 & 3900 & 7800 \\
\hline (1) & & & & \\
\hline
\end{tabular}

Yukarıda test sonuçlarının verildiği tablo, laboratuvar ortamında yapılan uygulamaların verilerinin ortalamasından elde edilmiştir. Figür 1'de IV nolu uygulama alanından alınan ve Sarcinomyces cinsi türlerini içeren örnekte laboratuvar ortamında yapılan testler sonucundaki gelişim farkları dikkati çekmektedir. Figür 1a'da \% 0.01 yoğunlukta antimoos uygulanmış, Figür $1 b^{\prime}$ de ise \% 3’lük antimoos uygulanmıştır. Figür 1 a'da oldukça iyi bir gelişim gösterdiği gözlenen hiflerin ge- 
lişiminin b'de tamamen durduğu açıkça ortadadır.
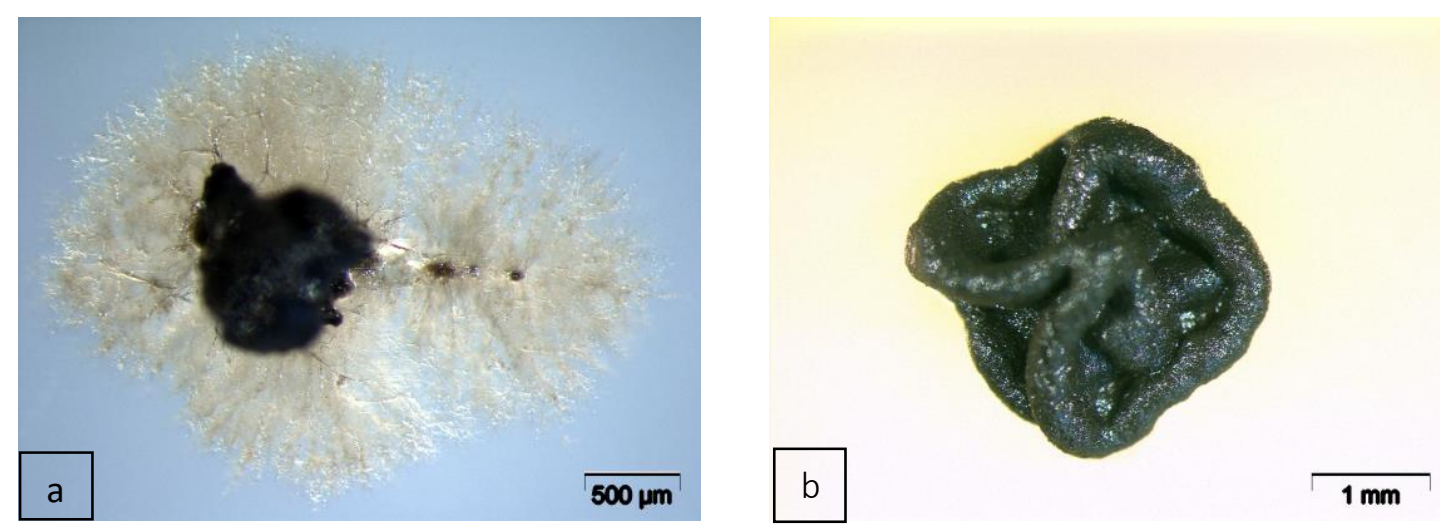

Figür 1. Antimoos uygulanması sonucunda Sarcinomyces sp. gelişimi; Konsantrasyon: a: \% 0.01, b: \% 3

Phaselis antik kentindeki tarihi eserlerde yoğun olarak bulunan türler Coniosporium cinsi üyeleridir. Bu cinsin ardından Capnobotryella ve Sarcinomyces cinslerinin üyeleri en yüksek sayıya sahiptir. Üzerinde deneme yapılan tarihi eserlerden I, II ve III nolu eserlerde yapılan incelemeler bu taşlar üzerinde Coniosporium cinsi üyelerinin, IV nolu eserde Sarcinomyces, V nolu eserde ise Capnobotryella türlerinin yoğun olarak bulunduğunu göstermiştir.

Laboratuvar ortamında uygulanan TTC testlerinde uygulama alanlarından alınan parçacıkların gözlemlenmesi sonucunda; $\vee$ nolu alanda \% 0.01 yoğunluktaki Polietilenimin uygulanması sonrası alınan örneğe ait testte taş parçacığının büyük bir kısmı kırmızı renkle boyanırken, \% 3 yoğunlukta Preventol R80 uygulanan IV nolu alanın hemen hemen hiç boyanmadığı gözlemlenmiştir. Tablo 1 incelendiğinde yapılan uygulama sonucunda \% 0.01 yoğunluktaki Polietilenimin testinde $\mathrm{V}$ nolu alanda ortalama 11000 koloni, IV nolu alanda ortalama 100 koloni sayıldığı görülmektedir. Figür 2'de TTC testi uygulanmış bir örnek gösterilmektedir.

\section{Tartışma ve Sonuç}

Tarihi eserleri, üzerlerinde yaşayan mikroorganizmaların zararlı etkilerinden korumaya yönelik bir araştırma olan bu çalışmada tarihi eserlerin bakımıkorunması çalışmalarında kullanılan biyositlerden olan Preventol A8, Preventol R80, Alkil Benzil Dimetil Amonyum Klorid, Trisiklazol, Bismut 2-3 di merkaptopropanol, Polietilenimin (permeabilizatör) ve Antimoos'un farklı dozları tarihi yapıların enfekte olmuş kısımlarından alınan örneklere uygulanmıştır.

Tablo 1 incelendiğinde ilk dikkati çeken nokta biyosit konsantrasyonu arttıkça ortamdaki canlılığın azalması üremenin durma noktasına gelmesidir. Tablo 1'de I, II ve III nolu uygulama alanların-

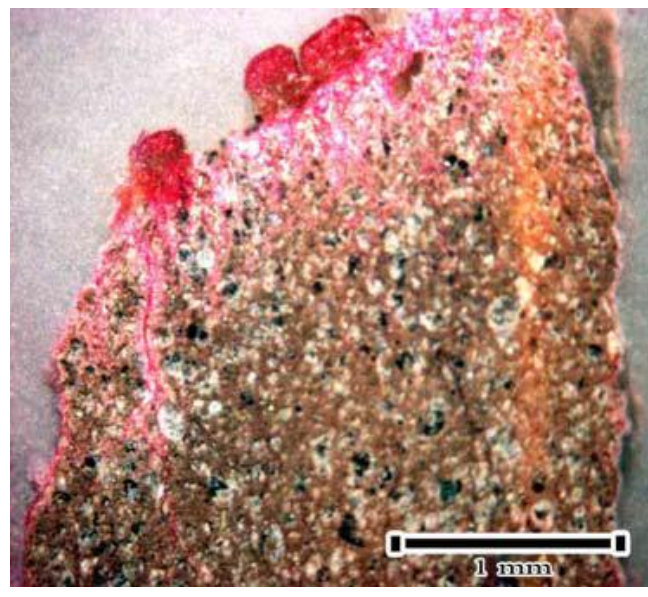

Figür 2. III nolu alanda \% 1 yoğunlukta Preventol A8 uygulanması sonrasında yapılan TTC testi sonrası görüntü da Coniosporium cinsi üyeleri, IV nolu alanda Sarcinomyces, V nolu alanda ise Capnobotryella türleri çoğunlukla yaşamaktadır.

Preventol A8 uygulamalarının sonuçları incelendiği zaman en iyi sonucun genellikle Sarcinomyces türlerinin yaşadığı III nolu uygulama alanında \%3 konsantrasyonda alındığı gözlenmektedir. 
Bu kimyasalın en az etkili olduğu uygulama ise Capnobotryella türlerinin bulunduğu V nolu bölgedir.

Preventol R 80 Coniosporium ve Sarcinomyces türlerinin bulunduğu I, II, III ve IV nolu alanlarda etkindir. Fakat yine de en iyi sonucu IV nolu alanda \% 3 konsantrasyondaki ugulama vermiştir. Toplamda sadece ortalama 100 koloni sayılmıştır.

Alkil Benzil Dimetil Amonyum Klorid, Trisiklazol, Bismut 2-3 di merkaptopropanol, Polietilenimin(permeabilizatör) ve Antimoos'un farklı dozlarının uygulama sonuçları ile Preventol A8 ve Preventol R80 testleri ile sonuçların benzer olduğu görülmektedir. Tüm kimyasallar en iyi etkiyi \% 3 konsantrasyonda ve IV nolu alanda göstermişlerdir. Tablo 1 deki veriler daha ayrıntılı olarak incelenecek olursa biyositlerin etki derecelerinin I, II, III de yaklaşık olarak aynı sonuçları gösterdiği, IV'te etkinin maksimum olduğu, V'te ise minimum olduğu görülmektedir. Bu durumda uygulama yapılan tarihi eserin üzerinde yaşayan mikroorganizmaların önemli bir rol oynadığı düşünülmektedir. Tüm biyositlerin maksimum etkiyi gösterdiği IV nolu alanda yaşayan Sarcinomyces türlerinin hücre çeperleri I, II ve III nolu bölgedeki Coniosporium türlerine göre daha zayıf, V nolu alanda yaşayan Capnobotryella üyelerine göre ise oldukça zayıftır. Dolayısıyla kimyasalların en iyi nüfuz edebildiği cins Sarcinomyces'tir. Capnobotryella'da ise durum bunun tam tersidir. Bu cins üyelerinin bulunduğu $\mathrm{V}$ nolu alandaki uygulama sonuçları incelenirse tüm biyositlerde minimum etkinin alınabildiği rahatlıkla görülebilir.

Aşağıda farklı konsantrasyonlardaki uygulamaların daha kolay karşılaştırılabilmesi açısından grafikler verilmştir (Tablo 2. A, B, C, D, E).

Genel olarak Tablo 1 ve özelikle Tablo 2.A'daki verilere göre biyositlerin tüm konsantrasyonlarının etkileri birbirleri ile karşılaştırıldığında siyah mikromantarlar üzerinde en etkili biyositin Preventol R 80, en az etki gösteren biyositin ise Trisiklazol olduğu gözlenmektedir.

\% 0.01 yoğunluktaki uygulamalarda en etkin çalışan biyosit Preventol R80'dir. \% 0.1'de Alkil Benzil Dimetil Amonyum Klorid, \% 1 ve \% 3 yoğunluktaki uygulamalarda ise yine Preventol $R$ 80 'in diğerlerine göre daha iyi sonuç verdiği Tablo 2'de açıkça görülmektedir.

Tablo 2. Araştırma alanında kullanılan biyositlerin etkileri ile ilgili hazırlanan grafikler: A) Kullanılan tüm biyositlerin tüm konsantrasyonlarının değerlendirilmesi, B) \% 0.01, C) \% 0.1, D) \% 1, E) \% 3 yoğunluktaki uygulamaların değerlendirilmesi
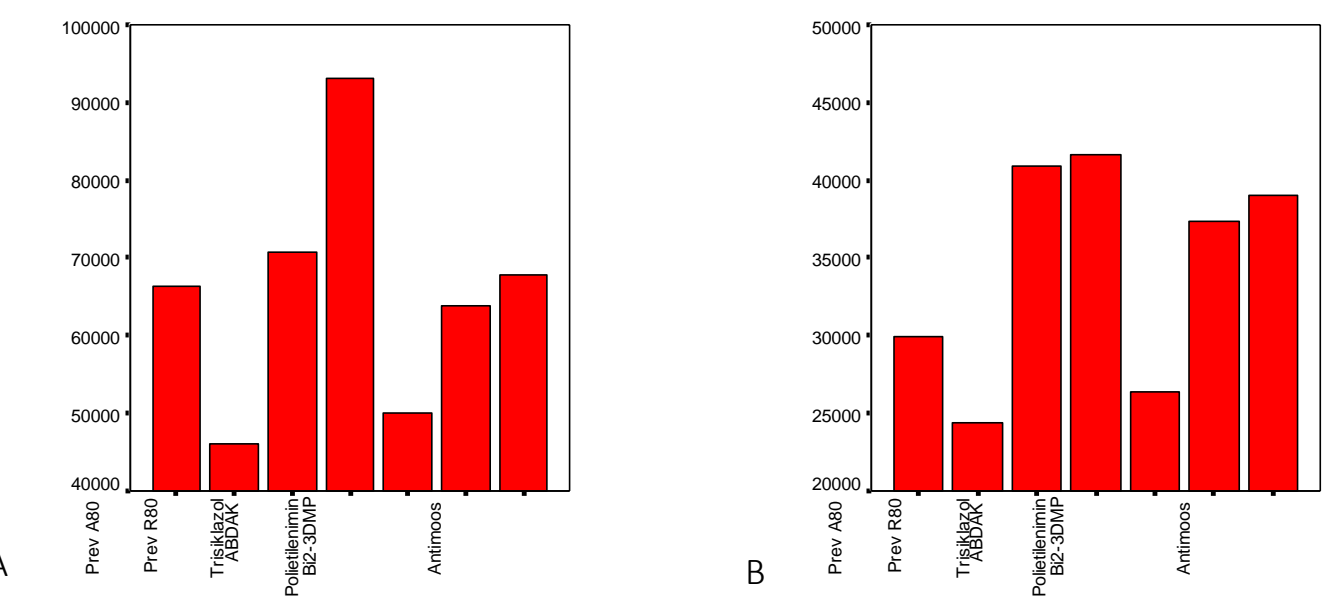

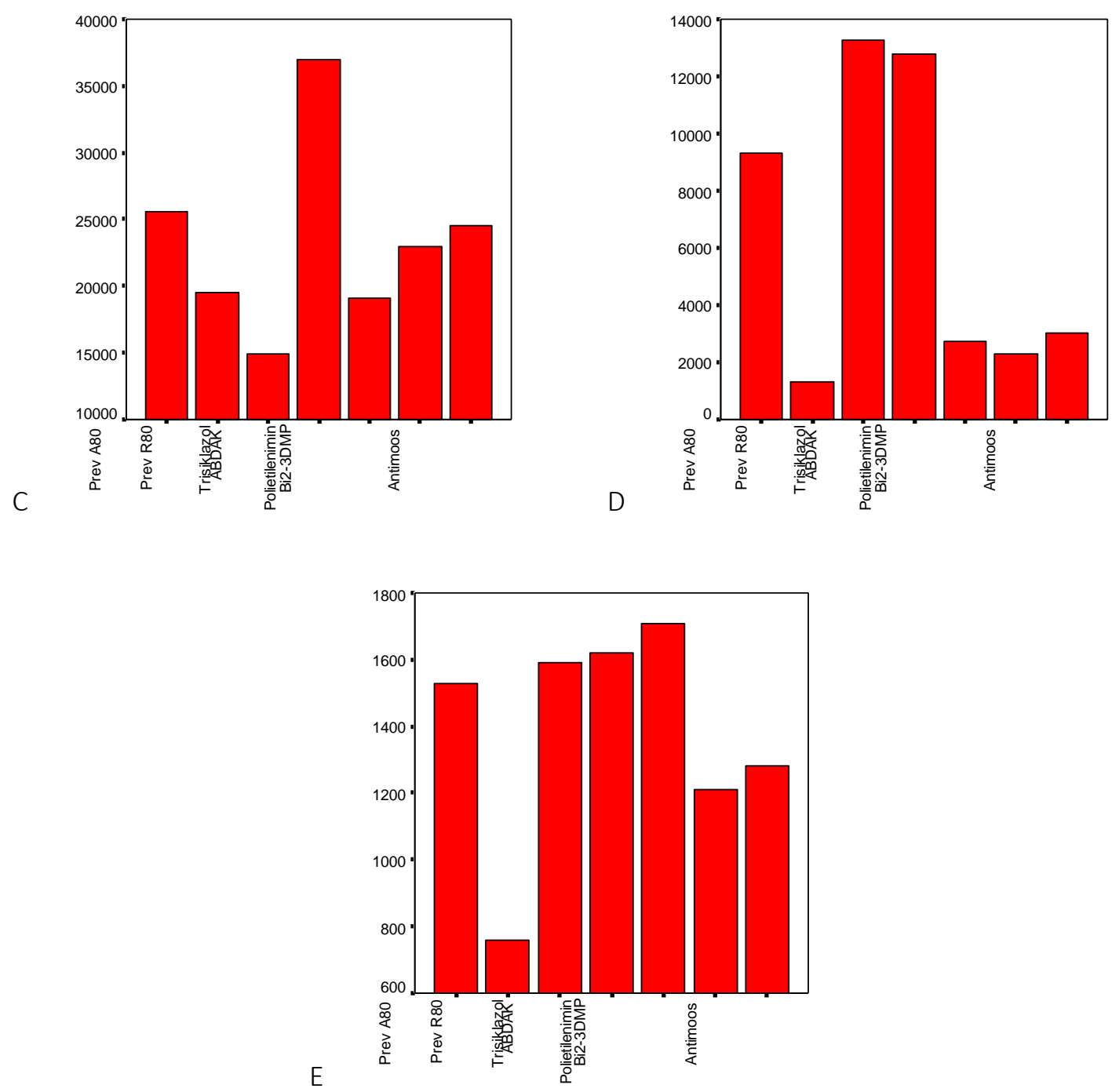

Bu çalışmadan elde edilen sonuçlar tarihi eserlerde restorasyon ve bakım işlemleri esnasında mikroorganizma etkilerine karşı kimyasal kullanma intiyacı duyulduğu zaman kulanılabilecektir. Başta siyah mikromantarlar olmak üzere diğer mikromantar çeşitleri üzerinde de en başarılı sonuç \% 3 konsantrasyondaki Preventol R 80 kullanımıyla elde edilmiştir. Bu dozdan daha yoğun konsantrasyonların kullanılmasının çevre sağlığı açııından sakıncalı sonuçlar doğurabileceği gözardı edilmemelidir. 
Bills et al. 2004

Bogolomova \& Minter 2003

de Hoog \& Guarro 1995

de Leo et al. 1999

Diakumaku et al. 1995

Eckhardt 1985

Ellis 1971

Ellis 1976

Gorbushina et al. 1994

Gravesen et al. 1994

Hawksworth 1969

Krumbein 1969

Ruibal et al. 2005

Selbmann et al. 2004

Sert et al. 2007a

Sert et al. 2007b

Sterflinger \& Krumbein 1997

Sterflinger et al. 1997

\section{BİBLIYOGRAFYA}

G. F. Bills, J. Collado, C. Ruibal, F. Pelaez, G. Platas, "Hormonema carpetanum sp. nov., a new lineage of dothideaceous black yeasts from Spain". Studies in Mycology 50 (2004) 149-157.

E. V. Bogolomova \& D. W. Minter, "Phaeococcomyces chersonesos, a new microcolonial lithobiontic fungus from marble in Chersonesus (Crimea, Ukraine)". Mycotaxon 86 (2003) 195-204.

G. S. de Hoog \& J. Guarro (eds), Atlas of Clinical Fungi. Centralbureau voor Schmimmelcultures. Baarn 1995.

F. de Leo, C. Urzi, G. S. de Hoog, "Two Coniosporium species from rock surfaces". Studies in Mycology 43 (1999) 70-79.

E. Diakumaku, A. A. Gorbushina, W. E. Krumbein, L. Panina, S. Soukharjevski, "Black fungi in marbles and limestones- An aesthetical, chemical and physical problem for the conservation of monuments". Sci. Total Environ 167 (1995) 295-304.

F. E. W. Eckhardt, "Solublization, transport, and deposition of mineral cations by micro-organisms-efficient rock weathering agents". Şurada: Ed. J. Drever, The Chemistry of Weathering 149 (1985) 161-173. Dordrecht.

M. B. Ellis, Dematiaceous Hyphomycetes. Commonwealth Mycological Institute, Kew, Surrey 1971.

M. B. Ellis, More Dematiaceous Hyphomycetes. Kew, Surrey, England: Commonwealth Mycological Institute.

A. A, Gorbushina, W. E. Krumbein, C. H. Hamman, L. Panina, S. Soukharjevski, U. Wollenzien, "Role of black fungi in color change and biodeterioration of antique marbles". Geomicrobiology Journal 11 (1994) 205-220.

S. Gravesen, J. C. Frisvad, R. A. Samson, Micro-fungi. Damaging effects on building materials. Munksgaard, Copenhagen 1994.

D. L. Hawksworth, "The lichenicolous Hyphomycetes". Bull. Br. Mus. Bot. Ser. 6 (1969) 183-300.

W. E. Krumbein „Über den Einfluss der Mikroflora auf die exogene Dynamik (Verwitterung und Krustenbildung)“. Geol. Rudsch. 58 (1969) 333-363.

C. Ruibal, G. Platas, G. F. Bills, "Isolation and characterization of melanized fungi from limestone formations in Mallorca". Mycological Progress 4 (2005) 1-23.

L. Selbmann, G. S. de Hoog, A. Mazzaglia, E. I. Friedmann, S. Onofri, "Fungi at the edge of life: cryptoendolithic black fungi from Antarctic deserts". Studies in Mycology 51 (2004) 8-38.

H. B. Sert, H. Sümbül, K. Sterflinger, "Microcolonial fungi from antique marbles in Perge/Side/Termessos (Antalya/Turkey)". Antonie van Leeuvenhoek 91/3 (2007) 217-227.

H. B. Sert, H. Sümbül, K. Sterflinger, "A New Species of Capnobotryella from monument surfaces". Mycological Research 111 (2007) 12351241.

K. Sterflinger, W. E. Krumbein, "Dematiaceous fungi as a major agent of biopitting for Mediterranean marbles and limestones". Geomicrobiology Journal 14 (1997) 219-230.

K. Sterflinger, R. de Baere, G. S. de Hoog, R. de Wachter, W. E. 
Sterflinger et al. 1999

Wollenzien 1997
Krumbein, "Coniosporium perforans and Coniosporium apollinis, two new rock inhabiting fungi isolated from marble in the Sanctuary of Delos (Cyclades, Greece)". Antonie van Leeuwenhoek 72 (1997) 349-363. K. Sterflinger, W. E. Krumbein, T. Lellau, J. Rullkötter, "Two cases of biogenic patina formation on rock". Ancient Biomolecules 3 (1999) 5165.

U. Wollenzien, G. S. de Hoog, W. E. Krumbein, J. M. J. Uijthof, "Sarcinomyces petricola, a new microcolonial fungus from marble in the Mediterranean basin". Antonie van Leeuwenhoek 71 (1997) 281-288. 